\title{
Synapsin Isoforms and Synaptic Vesicle Trafficking
}

\author{
Sang-Ho Song ${ }^{1,2}$, and George J. Augustine ${ }^{1,2, *}$
}

\begin{abstract}
Synapsins were the first presynaptic proteins identified and have served as the flagship of the presynaptic protein field. Here we review recent studies demonstrating that different members of the synapsin family play different roles at presynaptic terminals employing different types of synaptic vesicles. The structural underpinnings for these functions are just beginning to be understood and should provide a focus for future efforts.
\end{abstract}

\section{INTRODUCTION}

Synapsins are key regulators of synaptic vesicle (SV) dynamics in presynaptic terminals (Gitler et al., 2008; Hilfiker et al., 1999) The best-known function of these proteins is to regulate synaptic transmission by controlling the storage and mobilization of SVs within a reserve pool (RP) (Hilfiker et al., 1999). However, synapsins also influence other stages of SV trafficking, including SV fusion with the plasma membrane (Hilfiker et al., 1999, 2005; Medrihan et al., 2013), and are known to interact with proteins involved in endocytosis (Evergren et al., 2004), suggesting a potential role in endocytosis as well.

In vertebrates, synapsins are encoded by three distinct genes: synapsins I, II, and III (Fig. 1; Hosaka and Sudhof, 1998; Kao et al., 1998; Südhof et al., 1989). Mutations in synapsins I and II have been linked to epilepsy susceptibility in humans (Cavalleri et al., 2007; Garcia et al., 2004). This is consistent with observations in mouse models, where epileptic seizures are observed in mice in which the genes for synapsins I, II or I/I/IIII have been knocked out (Gitler et al., 2004b; Li et al., 1995; Rosahl et al., 1995). Synapsins II and III also have been implicated in schizophrenia, either because their expression levels are lowered in schizophrenia patients (Dyck et al., 2011; Mirnics et al., 2000; Tan et al., 2014; Vawter et al., 2002) or because of single-nucleotide polymorphisms associated with schizophrenia (Porton et al., 2011).

Alternative splicing of each synapsin gene produces 5 main

\footnotetext{
${ }^{1}$ Lee Kong Chian School of Medicine, Singapore 637553, Singapore, ${ }^{2}$ Institute of Molecular and Cell Biology, Singapore 138673, Singapore *Correspondence: george.augustine@ntu.edu.sg
}

Received 31 August, 2015; revised 9 November, 2015; accepted 10 November, 2015; published online 20 November, 2015

Keywords: neurotransmitter release, presynaptic terminals, synapsins, synaptic vesicles, vesicle trafficking isoforms consisting of combinations of numerous structural domains (Fig. 1). The $\mathrm{N}$-terminal portions of all synapsin isoforms (domains A-C) are highly conserved, while the C-terminal portions (domains D-J) differ between isoforms. As will be discussed below, recent data indicates that different synapsin isoforms perform different functions in neurons. These unique functions presumably are mediated by the variable C-terminal domains, though of course the conserved portions also have important functions as well. In this mini-review, we will attempt to reconcile synapsin structure and function.

\section{PROPERTIES OF SYNAPSIN DOMAINS}

Given that their conserved and variable domains must mediate all synapsin functions, we will briefly summarize what is now known about each of these domains.

\section{Conserved domains}

Domain $A$ is known to interact with phospholipids, with this interaction neutralized by phosphorylation of a serine that is phosphorylated by cAMP-dependent protein kinase (PKA) and $\mathrm{Ca}^{2+}$ /calmodulin-dependent protein kinase I (CaMKI) (Hosaka and Südhof, 1999). Injection of a peptide derived from domain A inhibits release of the excitatory neurotransmitter, glutamate, without affecting vesicle pool size or neurotransmitter release kinetics (Hilfiker et al., 2005). This effect requires dephosphorylation of the phosphorylation site, suggesting that the peptide may work by interfering with phosphorylation-sensitive binding of synapsins to phospholipids. Thus, phospholipid binding may be central to the function of synapsins in neurotransmitter release.

Domain $B$ is a conserved linker that connects domains $A$ and $\mathrm{C}$. This domain has many amino acids, such as alanine and serine, that have compact conformations. Little is known about the function of domain $\mathrm{B}$; the fact that it contains a phosphorylation site for the mitogen-activated protein kinase (MAPK)/Extracellular signal-regulated kinase (Erk) presumably confers regulation of synapsin function by this signalling pathway (Jovanovic et al., 1996).

Domain $\mathrm{C}$ is the region with the most extensive homology across synapsins and mediates many of the core functions of synapsins, such as interactions with the actin cytoskeleton and SV phospholipids (Cheetham et al., 2001). This domain is amphipathic - containing both hydrophobic and highly charged residues - and is characterised by a compact structure of roughly elliptical shape, composed of several subdomains organized as $\alpha$-helices or $\beta$-sheets, as well as a disordered region at its 
C-terminus (Esser et al., 1998). There are several amino acids flanked by charged residues. Domain $\mathrm{C}$ partially inserts into the hydrophobic phase of phospholipid bilayers, potentially mediating binding of synapsins to SVs (Südhof et al., 1989). Domain $\mathrm{C}$ also mediates homo- and heterodimerization of synapsins (Brautigam et al., 2004; Hosaka and Südhof, 1999). Disruption of $\mathrm{C}$ domain function by peptide microinjection indicates domain $\mathrm{C}$ interactions maintain the RP of SVs and regulate the kinetics of neurotransmitter release; these actions have been attributed to interfering with binding of synapsins to the actin cytoskeleton (Hilfiker et al., 2005).

\section{Variable domains}

The C-terminal region of each synapsin isoform is a combination of variable domains that determines the identity and unique functional properties of each isoform. All of these variable domains are proline-rich.

Domain $\mathrm{D}$ is 27 percent proline and 17 percent glutamine residues, whereas asparagine is totally excluded (Südhof et al., 1989). This domain binds to SH3-domain containing proteins, such as c-Src, Grb2, PI3K, PLC-r and amphiphysin-I and II, as well as CaMKII and Rab3 (Giovedì et al., 2004). Domain D contains two CaMKIl phosphorylation sites (Fig. 1) and phosphorylation of these sites has been implicated in regulation of glutamate release (Chi et al., 2003; Llinás et al., 1991). Domain D apparently serves to inhibit targeting of synapsin lb to SVs (Gitler et al., 2004a).

Domain E is common to all 'a' synapsin isoforms (Fig. 1). Microinjection of a peptide from domain $E$ reduces the RP and slows release kinetics, indicating that this domain is involved both in maintaining the RP and in synchronizing exocytosis (Hilfiker et al., 1998; 2005). It has been reported that domain $\mathrm{E}$ also mediates synapsin I oligomerization and cross-links SVs (Monaldi et al., 2010). For targeting of synapsins to presynaptic terminals, domain $\mathrm{E}$ overrides the inhibitory effect of the Cterminus of domain D (Gitler et al., 2004a). The molecular mechanism underlying this action of domain $E$ is unknown.

Domain $\mathrm{G}$ in synapsins $\mathrm{Ila}$ and $\mathrm{Ilb}$, as well as domain $\mathrm{H}$ in synapsin Ilb, are proline-rich domains of uncertain function. Domains $\mathrm{F}$ and I are found only at the C-terminal ends of ' $\mathrm{b}$ ' type isoforms; their functions also are poorly understood.

Domain $\mathrm{J}$ is unique to synapsin Illa and has a high content of proline, glutamine, serine, and alanine residues (Hosaka and

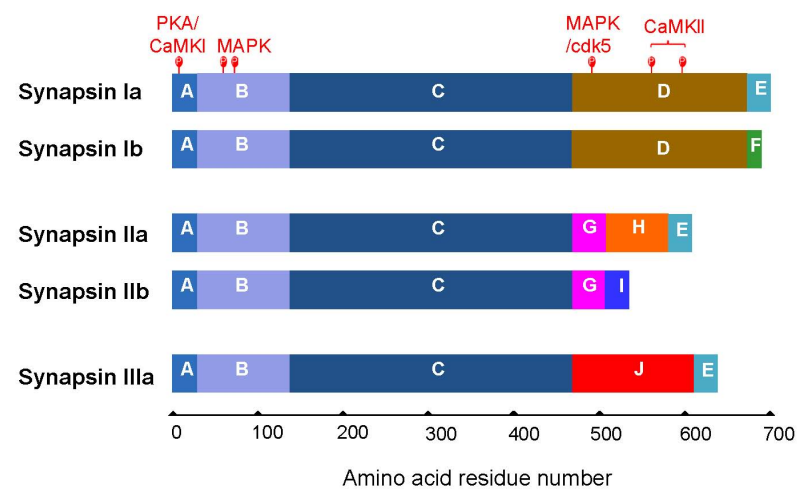

Fig. 1. Domain model of the vertebrate synapsin family. Experimentally determined phosphorylation sites within synapsin la are indicated, along with the kinases that phosphorylate these sites. Scale at bottom shows amino acid number.
Südhof, 1998; Kao et al., 1998). Although the function of this domain is unknown, it must be important for the roles of synapsin Illa in release of dopamine and GABA (see below). This domain also contains a MAPK phosphorylation site, S470, that is mutated in some schizophrenia patients (Porton et al., 2004).

\section{MULTIPLE SYNAPSIN FUNCTIONS IN NEUROTRANSMITTER RELEASE}

Next we will summarize what is known about the functions of synapsins in release of neurotransmitters. Our conclusion is that synapsins have different functions in different types of neurons, because loss of synapsins differentially affects transmission in different neuron types. Key determinants of synapsin function apparently are the types of neurotransmitters and SVs employed in the presynaptic terminal, as well as the synapsin isoforms expressed.

\section{Glutamatergic synapses}

Perturbation of synapsin function - using antibodies, peptides or gene deletion - selectively reduces the number of SVs in the RP defined as SVs residing away from the active zone (Gitler et al., 2004b; Hilfiker et al., 1998; Pieribone et al., 1995; Rosahl et al., 1995). Consistent with a role for synapsins in maintaining the $\mathrm{RP}$, the rate of synaptic depression - which is thought to be limited by mobilization of SVs from the RP - is faster in glutamatergic hippocampal neurons from synapsin triple knock-out (TKO) mice (Fig. 2A; Gitler et al., 2004b). Despite this dramatic physiological phenotype, the number of docked SVs are unaffected by loss of synapsins and basal synaptic transmission is unaffected (Fig. 2A; Gitler et al., 2004b). This indicates that synapsins tether glutamatergic vesicles within the RP and, thereby, regulate the size of the RP. Remarkably, synapsin lla is the only isoform that significantly rescues the kinetics of synaptic depression and RP size when introduced into TKO neurons (Gitler et al., 2008). The degree of rescue of SV number by different synapsin isoforms is directly proportional to the kinetics of synaptic depression, demonstrating that (1) the rate of synaptic depression is determined by the density of glutamatergic SVs in the nerve terminal; and (2) synapsins, specifically synapsin Ila, determine SV density within the RP (Gitler et al., 2008).

\section{GABA release}

In contrast to glutamate release, GABA release from interneurons from synapsin TKO mice have a completely different physiological phenotype: basal transmission, as measured by inhibitory postsynaptic currents (IPSCs) evoked by single stimuli, is greatly reduced while the speed of synaptic depression is unaffected (Fig. 2B; Gitler et al., 2004b; Medrihan et al., 2013). Similarly, the number of SVs docked at active zones is reduced in GABAergic nerve terminals from TKO mice (Gitler et al., 2004b). This indicates that synapsins regulate a late step in SV trafficking that precedes (and controls) fusion of GABAergic SVs during exocytosis. Which synapsin isoform(s) regulate GABA release is not yet clear. Basal inhibitory transmission is reduced in mice lacking either synapsin I or synapsin III, while synapsin II deletion paradoxically increases inhibitory transmission (Baldelli et al., 2007; Feng et al., 2002; Medrihan et al., 2013). A preliminary report suggests that IPSC amplitude can be rescued by any of the 5 major synapsin isoforms (Song and Augustine, 2014). In summary, both the modes of action and synapsin isoforms involved are different for GABAergic and glutamatergic SVs. 

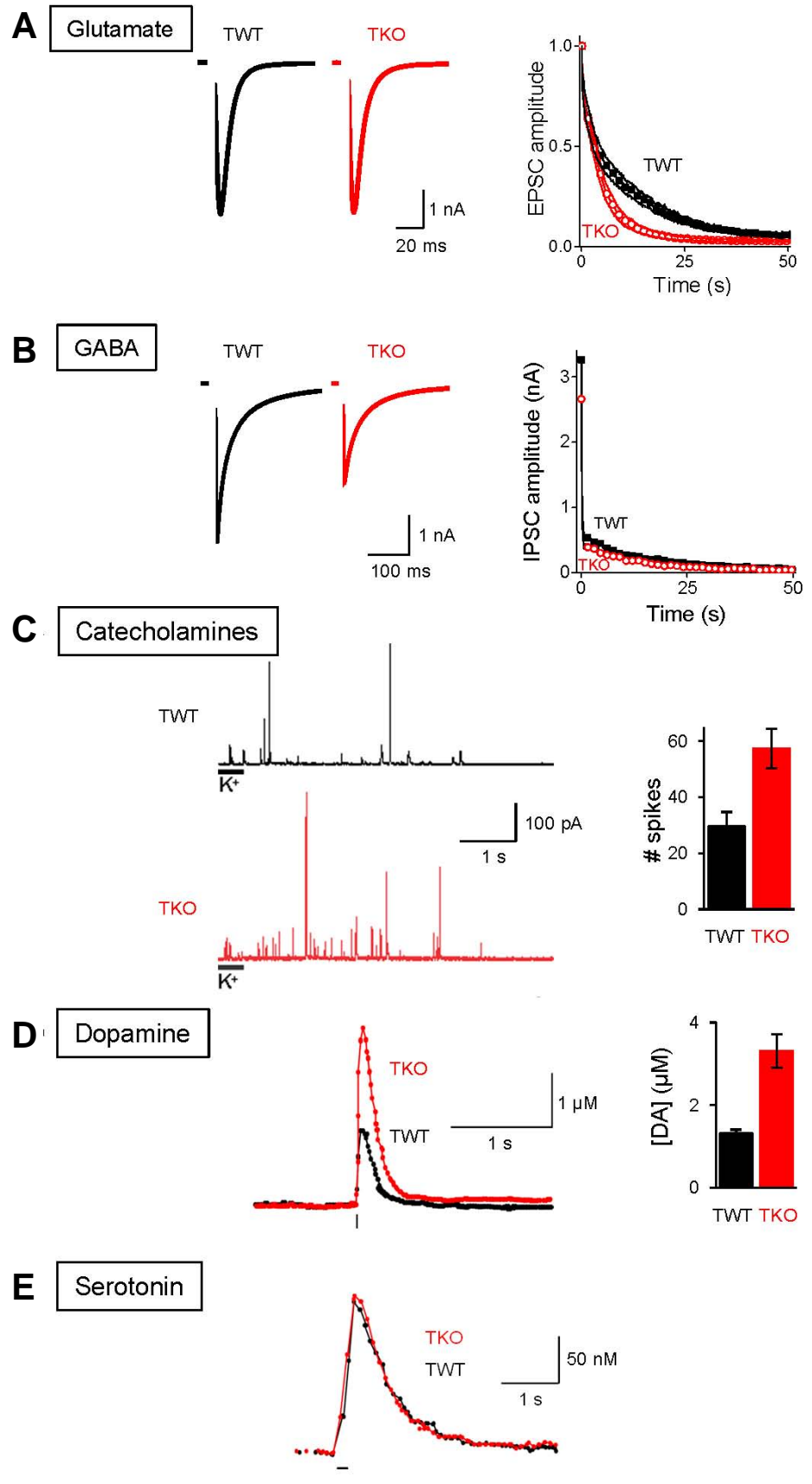

\section{Release of biogenic amines}

Deletion of all synapsin isoforms increases the amount of catecholamine released from depolarized chromaffin cells (Villanueva et al., 2006). This increase is not caused by changes in the amount of catecholamine released per vesicle or in the speed of discharge of catecholamines from individual vesicles, but instead is due to an increased rate of exocytotic events (Fig. 2C). This effect is rescued by synapsin lla, indicating that this synapsin isoform serves as a negative regulator of catecholamine release. Thus, synapsin lla seems to have different, and potentially opposite, roles for vesicles containing glutamate versus catecholamines.

Synapsins have differential actions in release of two mono-
Fig. 2. Effect of synapsin deletion on neurotransmitter release at different synapses and chromaffin cells. (A) Neurotransmitter release at a glutamatergic synapse. Left -excitatory postsynaptic currents (EPSCs) evoked by single stimuli, recorded from autaptic cultures of hippocampal excitatory neurons from synapsin triple wild-type (TWT) and triple knock-out (TKO) mice. Right - kinetics of synaptic depression, evident as a decline in mean amplitude of EPSCs evoked by trains of stimuli ( 500 at $10 \mathrm{~Hz}$ ). Replotted from data in Gitler et al. (2004b). (B) Neurotransmitter release at a GABAergic synapse. Left - inhibitory postsynaptic currents (IPSCs) evoked by single stimuli, recorded from autaptic cultures of hippocampal inhibitory neurons from TWT and TKO mice. Right - kinetics of synaptic depression, evident as a decline in mean amplitude of IPSCs evoked by trains of stimuli $(500$ at $10 \mathrm{~Hz}$ ). Replotted from data in Gitler et al. (2004b). (C) Catecholamine release from cultured adrenal chromaffin cells. Left - Representative amperometric measurements of exocytotic discharge of catecholamine (spikes) from TWT and TKO cells in response to treatment with a highpotassium $\left(60 \mathrm{mM} \mathrm{K}^{+}\right)$during times indicated by horizontal bars. Right - comparison of number of catecholamine release spikes evoked in TWT and TKO cells. Replotted from data in Villanueva et al. (2006). (D) Dopamine (DA) release evoked by a single electrical stimulus (vertical black line) in striatal brain slices from TWT and TKO mice. Left - Representative responses. Right - mean [DA] measured in slices from each genotype (right). Replotted from data in Kile et al. (2010). (E) Representative traces of serotonin release evoked by electrical stimulation (100 $\mathrm{Hz}, 20$ pulses, black line) from substantia nigra in brain slices from TWT and TKO mice. Replotted from data in Kile et al. (2010). amine neurotransmitters, dopamine (DA) and serotonin (5-HT). While loss of synapsins increases DA release from presynaptic terminals (Fig. 2D), there is no difference in $5-\mathrm{HT}$ release between wild-type and TKO mice (Fig. 2E; Kile et al., 2010). The negative regulation of DA release apparently is mediated by synapsin IIla, because a similar enhancement of DA release occurs in synapsin Illa KO mice. In addition, synapsins appear to provide a RP of DA-containing vesicles (DA vesicles); this $\mathrm{RP}$ is recruited during cocaine treatment and is reduced in synapsin TKO mice (Venton et al., 2006). In summary, synapsins appear to have two effects in trafficking of DA vesicles: an inhibitory effect on exocytosis of DA vesicles, mediated by synapsin IIla, and maintenance of a RP of DA vesicles, mediated 
by a synapsin isoform (or isoforms) that remains to be determined.

\section{STRUCTURAL BASIS FOR SYNAPSIN FUNCTIONS}

Results described in the preceding section demonstrate that synapsins have different physiological roles in trafficking of different types of SVs and reveal that these functions are subserved by different synapsin isoforms. The current challenge is to understand these different roles of synapsins in molecular terms. In this section we use the known molecular properties of different synapsin isoforms and their constituent domains in a preliminary attempt to explain these physiological actions of synapsins.

The mechanisms that target synapsins to presynaptic terminals may provide clues to the actions of synapsin Ila in maintaining the RP of glutamatergic SVs. The crucial domains required for presynaptic targeting of synapsins to glutamatergic terminals are domains $\mathrm{B}, \mathrm{C}$ and $\mathrm{E}$; domain $\mathrm{A}$ is not necessary, though its presence enhances SV targeting (Gitler et al., 2004a). This is consistent with roles for both domains $A$ and $C$ in phospholipid binding. Domain D inhibits SV targeting, an effect that can be overcome by domain $\mathrm{E}$. This can explain why microinjection of domain $E$ peptides inhibits glutamate release (Hilfiker et al., 1998). Further, it can explain why synapsin lb cannot target to presynaptic terminals: this isoform lacks domain $\mathrm{E}$, which is required to overcome the inhibitory effect of domain D. Synapsin lla has all of the domains that enhance SV targeting but does not have the inhibitory $D$ domain. Instead, this isoform has domain $\mathrm{G}$, a very short, proline-rich region that potentially could enhance synapsin lla binding to SVs. These structural differences might underlie the ability of synapsin lla to support the glutamatergic RP, given that binding and cross-linking of SVs appears important for the ability of synapsins to maintain the RP (Monaldi et al., 2010). Synapsin Ilb also has domain G, but its lack of domain $\mathrm{E}$ may hinder its ability to bind to SVs as well as synapsin lla can; to date, there have been no experimental comparisons of SV binding properties of synapsins Ila and Ilb.

The observation that loss of synapsins affects basal transmission at inhibitory synapses indicates that synapsins have a different mechanism of action in trafficking of GABAergic SVs. The fact that multiple synapsin isoforms can rescue the TKO phenotype points toward a role for the conserved domains $(A$, $B$, and/or $C$ ) in this action. Domain $C$ is known to regulate the kinetics of transmitter release (Hilfiker et al., 2005), which could account for the changes in synchronization of GABA exocytosis observed in synapsin lla knock-out mice and TKO mice (Medrihan et al., 2013; Song and Augustine, 2014). However, which of the many binding activities associated with domain C could underlie this effect remains to be determined.

In regard to trafficking of SVs containing DA, the implication of synapsin IIla in DA release indicates that the basic functions of the conserved domains $\mathrm{A}, \mathrm{B}$, and $\mathrm{C}$ is modified by domain $\mathrm{J}$, which is unique to synapsin Illa. This should motivate further analysis of the binding properties and functions of this domain.

\section{CONCLUSIONS}

Recent studies indicate that each synapsin isoform subserves unique functions at different type of presynaptic terminals. Thus, while all synapsin isoforms share many structural features specifically domains A-C - they function differently due to the unique domain composition of their $\mathrm{C}$-termini. Further insights into the molecular properties of domains D-I clearly hold the key to understanding of the unique functions of each synapsin isoform. Once we understand how each synapsin isoform does its job, we finally will be able to answer the long-standing question of how synapsins contribute to neurotransmitter release.

Table 1. Summary of synapsin structure and function

\begin{tabular}{cccccc}
\hline \multirow{2}{*}{$\begin{array}{c}\text { Synapsin } \\
\text { isoform }\end{array}$} & \multirow{2}{*}{$\begin{array}{c}\text { Unique } \\
\text { domains }\end{array}$} & \multicolumn{4}{c}{ Rescues neurotransmitter release* } \\
\cline { 4 - 6 } & Glut & GABA & DA & 5-HT \\
\hline la & D/E & & $\sqrt{ }$ & & \\
lb & D/F & & $\sqrt{ }$ & & \\
Ila & E/G/H & $\sqrt{ }$ & $\sqrt{ }$ & \\
Ilb & G/l & & $\sqrt{ }$ & & \\
Illa & E/J & & $\sqrt{ }$ & $\sqrt{ }$ \\
\hline
\end{tabular}

${ }^{*}$ rescue refers to phenotype of synapsin TKO neurons in which the indicated synapsin isoform has been re-introduced.

\section{ACKNOWLEDGMENTS}

Supported by grant 2015-T1-001-069 from the Singapore Ministry of Education.

\section{REFERENCES}

Baldelli, P., Fassio, A., Valtorta, F., and Benfenati, F. (2007). Lack of synapsin I reduces the readily releasable pool of synaptic vesicles at central inhibitory synapses. J. Neurosci. 27, 1352013531.

Brautigam, C.A., Chelliah, Y., and Deisenhofer, J. (2004). Tetramerization and ATP binding by a protein comprising the A B, and C domains of rat synapsin I. J. Biol. Chem., 279, 1194811956.

Cavalleri, G.L., Weale, M.E., Shianna, K.V., Singh, R., Lynch, J.M., Grinton, B., Szoeke, C., Murphy, K., Kinirons, P., O'Rourke, D., et al. (2007). Multicentre search for genetic susceptibility loci in sporadic epilepsy syndrome and seizure types: a case-control study. Lancet Neurol. 6, 970-980.

Cheetham, J.J., Hilfiker, S., Benfenati, F., Weber, T., Greengard, P., and Czernik, A.J. (2001). Identification of synapsin I peptides that insert into lipid membranes. Biochem. J. 354, 57-66.

Chi, P., Greengard, P., and Ryan, T.A. (2003). Synaptic vesicle mobilization is regulated by distinct synapsin I phosphorylation pathways at different frequencies. Neuron 38, 69-78.

Dyck, B.A., Beyaert, M.G., Ferro, M.A., and Mishra, R.K. (2011) Medial prefrontal cortical synapsin II knock-down induces behavioral abnormalities in the rat: examining synapsin II in the pathophysiology of schizophrenia. Schizophr Res. 130, 250-259.

Esser, L., Wang, C.R., Hosaka, M., Smagula, C.S., C.Südhof, T.C., and Deisenhofer, J. (1998). Synapsin I is structurally similar to ATP-utilizing enzymes. EMBO J. 17, 977-984.

Evergren, E., Marcucci, M., Tomilin, N., Low, P., Slepnev, V., Andersson, F., Gad, H., Brodin, L., De Camilli, P., and Shupliakov, O. (2004). Amphiphysin is a component of clathrin coats formed during synaptic vesicle recycling at the lamprey giant synapse. Traffic 5, 514-528.

Feng, J., Chi, P., Blanpied, T.A, Xu, Y., Magarinos, A.M., Ferreira, A., Takahashi, R.H., Kao, H.-T., McEwen, B.S., Ryan, T.A., et al. (2002). Regulation of neurotransmitter release by synapsin III. J. Neurosci. 22, 4372-4380.

Garcia, C.C., Blair, H.J., Seager, M., Coulthard, A., Tennant, S., Buddles, M., Curtis, A., and Goodship, J.A. (2004). Identification of a mutation in synapsin I, a synaptic vesicle protein, in a family with epilepsy. J. Med. Genet. 41,183-186.

Giovedì, S., Darchen, F., Valtorta, F., Greengard, P., and Benfenati, F. (2004). Synapsin is a novel Rab3 effector protein on small synaptic vesicles: II. Functional effects of the Rab3A-synapsin I interaction. J. Biol. Chem. 279, 43769-43779. 
Gitler, D., Xu, Y., Kao, H.-T., Lin, D., Lim, S., Feng, J., Greengard, P., and Augustine, G.J. (2004a). Molecular determinants of synapsin targeting to presynaptic terminals. J. Neurosci. 24, 3711-3720.

Gitler, D., Takagishi, Y., Feng, J., Ren, Y., Rodriguiz, R.M., Wetsel, W.C., Greengard, P., and Augustine, G.J. (2004b). Different presynaptic roles of synapsins at excitatory and inhibitory synapses. J. Neurosci. 24, 11368-11380.

Gitler, D., Cheng, Q., Greengard, P., and Augustine, G.J. (2008). Synapsin Ila controls the reserve pool of glutamatergic synaptic vesicles. J. Neurosci. 28, 10835-10843.

Hilfiker, S., Schweizer, F.E., Kao, H.T., Czernik, A.J., Greengard, P., and Augustine, G.J. (1998). Two sites of action for synapsin domain $\mathrm{E}$ in regulating neurotransmitter release. Nat. Neurosci. 1, 29-35.

Hilfiker, S., Pieribone, V.A., Czernik, A.J., Kao, H.T., Augustine, G.J., and Greengard, P. (1999). Synapsins as regulators of neurotransmitter release. Philos. Trans. R. Soc. Lond. B. Biol. Sci. 354, 269-279.

Hilfiker, S., Benfenati, F., Doussau, F., Nairn, A.C., Czernik, A.J., Augustine, G.J., and Greengard, P. (2005). Structural domains involved in the regulation of transmitter release by synapsins. J. Neurosci. 25, 2658-2669.

Hosaka, M., and Südhof, T.C. (1998). Synapsin III, a Novel Synapsin with an Unusual Regulation by $\mathrm{Ca}^{2+}$. J. Biol. Chem. 273, 13371-13374.

Hosaka, M., and Südhof, T.C. (1999). Homo- and heterodimerization of synapsins. J. Biol. Chem. 274, 16747-16753.

Jovanovic, J.N., Benfenati, F., Siow, Y.L., Sihra, T.S., Sanghera, J.S., Pelech, S.L., Greengard, P., and Czernik, A.J. (1996) Neurotrophins stimulate phosphorylation of synapsin I by MAP kinase and regulate synapsin I-actin interactions. Proc. Natl. Acad. Sci. USA 93, 3679-3683.

Kao, H.T., Porton, B., Czernik, A. J., Feng, J., Yiu, G., Häring, M., Benfenati, F., and Greengard, P. (1998). A third member of the synapsin gene family. Proc. Natl. Acad. Sci. USA 95, 4667-4672.

Kile, B.M., Guillot, T.S., Venton, B.J., Wetsel, W.C., Augustine, G.J., and Wightman, R.M. (2010). Synapsins differentially control dopamine and serotonin release. J. Neurosci. 30, 9762-9770.

Li, L., Chin, L.S., Shupliakov, O., Brodin, L., Sihra, T.S., Hvalby, O., Jensen, V., Zheng, D.,McNamara, J.O., Greengard, P., et al., (1995). Impairment of synaptic vesicle clustering and of synaptic transmission, and increased seizure propensity, in synapsin Ideficient mice. Proc. Natl. Acad. Sci. USA 92, 9235-9239.

Llinás, R., Gruner, J.A., Sugimori, M., McGuinness, T.L., Greengard P. (1991). Regulation by synapsin I and $\mathrm{Ca}^{2+}$-calmodulindependent protein kinase II of the transmitter release in squid giant synapse. J. Physiol. 436, 257-282.

Medrihan, L., Cesca, F., Raimondi, A., Lignani, G., Baldelli, P., and Benfenati, F. (2013). Synapsin II desynchronizes neurotransmitter release at inhibitory synapses by interacting with presynaptic calcium channels. Nat. Commun. 4, 1512.

Mirnics, K., Middleton, F.A., Marquez, A., Lewis, D.A., Levitt, P. (2000). Molecular characterization of schizophrenia viewed by microarray analysis of gene expression in prefrontal cortex Neuron 28, 53-67.

Monaldi, I., Vassalli, M., Bachi, A., Giovedì, S., Millo, E., Valtorta, F., Raiteri, R., Benfenati, F., and Fassio, A. (2010). The highly conserved synapsin domain $\mathrm{E}$ mediates synapsin dimerization and phospholipid vesicle clustering. Biochem. J. 426, 55-64

Pieribone, V.A., Shupliakov, O., Brodin, L., Hilfiker, S., Czernik, A.J., Greengard, P. (1995) Distinct pools of synaptic vesicles in neurotransmitter release. Nature 375, 493-497.

Porton, B, Ferreira, A, DeLisi, L.E, and Kao, H.T. (2004). A rare polymorphism affects a mitogen-activated protein kinase site in synapsin III: Possible relationship to schizophrenia. Biol. Psychiatry 55, 118-125.

Porton, B., Wetsel, W.C., Kao, H.T. (2011). Synapsin III: role in neuronal plasticity and disease. Semin Cell Dev. Biol. 22, 416-424.

Rosahl, T.W., Spillane, D., Missler, M., Herz, J., Selig, D.K., Wolff, J.R., Hammer, R.E., Malenka, R.C., Südhof, T.C. (1995). Essential functions of synapsins I and II in synaptic vesicle regulation. Nature 375, 488-493.

Song, SH., and Augustine, J.G. (2014). Synapsin isoforms regulating GABA release from hippocampal interneurons. Annual Meeting of Society for Neuroscience 783,12.

Südhof, T.C., Czernik, A.J., Kao, H.T., Takei, K., Johnston, P.A., Horiuchi, A., Kanazir, S.D., Wagner, M.A., Perin, M.S., and De Camilli, P. (1989). Synapsins: mosaics of shared and individual domains in a family of synaptic vesicle phosphoproteins. Science 245, 1474-1480.

Tan, M.L., Dyck, B.A., Gabriele, J., Daya, R.P., Thomas, N., Sookram, C., Basu, D., Ferro, M.A., Chong, V.Z., and Mishra, R.K. (2014) Synapsin II gene expression in the dorsolateral prefrontal cortex of brain specimens from patients with schizophrenia and bipolar disorder: effect of lifetime intake of antipsychotic drugs. Pharmacogenomics J.14, 63-69.

Vawter, M.P., Thatcher, L., Usen, N., Hyde, T.M., Kleinman, J.E., and Freed, W.J. (2002). Reduction of synapsin in the hippocampus of patients with bipolar disorder and schizophrenia. Mol. Psychiatry 7 , 571-578.

Venton, B.J., Seipel, A.T., Phillips, P.E.M., Wetsel, W.C., Gitler, D., Greengard, P., Augustine, G.J., and Wightman, R.M. (2006). Cocaine increases dopamine release by mobilization of a synapsin-dependent reserve pool. J. Neurosci. 26, 32063209.

Villanueva, M., Thornley, K., Augustine, G.J., and Wightman, R.M. (2006). Synapsin II negatively regulates catecholamine release. Brain Cell Biol. 35, 125-136. 